\title{
Common biases found in the workplace: visible and invisible inequalities
}

Veena Shenoy and Mohan Kumar

\section{Introduction}

Did you know that unconscious bias can affect our everyday choices and decisions unknowingly? Employees' backgrounds, experiences and social stereotypes could impact our choices and actions (Damaraju, 2018). Hence, all need to be aware and recognize the unconscious bias in us and challenge it. It also becomes essential for us to understand the biases in various situations through dialogues and discussions, make informed decisions and reflect upon our choices more consciously. Each one of us can help break the bias and make inclusion happen.

As practitioners, unconscious bias can impact key processes such as recruitment and selection (Connelly, 2020), work allocation, performance appraisals or promotion decisions (Bapuji and Chrispal, 2020). It can lead to inaccuracy or favoritism based on the team members' familiarity, gender, identity, age, race or sexual orientation (Swethaa Ballakrishnen, 2018).

Here are some biases which could negatively affect the decision-making.

- Affinity bias is our tendency to gravitate toward/prefer people similar to ourselves. For example, hiring or promoting someone of the same race, gender, age or educational background (Damaraju, 2018).

- Anchoring bias is a bias when there is a dependency on initial information shared as a base or anchor reference. For example, a colleague has over a decade's experience working for nonprofits. Now, she is joining a big tech firm; her prior experience indicates her value to the sales function.

- Attribution bias is a cognitive bias that refers to systemic errors we make by associating people's behaviors with their intrinsic nature. For example, someone is always late to meetings because he/she/they like to assert their importance.

- Blind-spot bias is a bias where we overlook our own cognitive biases (Jones, 2014). For example, a colleague identifies herself as a liberal and supports live-in relationships. However, she does not have an advocate for marriage for same-sex partners.

- Confirmation bias is a tendency to search, favor and recall information that confirms our preconceptions. For example, connecting with a preset idea that employees with disabilities are better suited for back-office operations while denying them equal opportunity for other roles.

- Conformity bias is a bias when our views are swayed or influenced by the opinions of other group members. It is widespread in group interactions. For example, in a panel
Veena Shenoy is based at the School of Management, National Institute of Technology Karnataka, Mangalore, India and Department of Human Resource, International School of Business and Research, Bangalore, India. Mohan Kumar is based at the Digital Technologies, Wipro Limited, Bangalore, India. 
discussion with subject matter experts, three of them succumbed to peer pressure and were swayed in favor of a cost-effective yet limiting solution for a client.

- Conservatism bias is a bias to established processes because they have been around for many years. For example, a colleague dismisses "work from home" as an effective workplace practice.

- Contract-effect bias is a bias where we evaluate one person's performance in contrast to another because of our interaction with the individuals simultaneously or in close succession. For example, during a hiring process, comparing two individuals who gave interviews simultaneously can lead to bias.

- Halo effect bias is a bias that tends to put someone on a pedestal or think more highly of them after learning something impressive about them (Martin, 2019). For example, a colleague's ideas are considered universal compared to other team members because he/she/they are from an ivy league business school.

- Horns effect bias is a bias where we form a negative perception about someone after learning something unfavorable about them. For example, some peers doubted a colleague's contribution to a project after learning he was allegedly charged with fraud in his previous company, an allegation that was later dismissed.

- Distance bias is a bias when we have global teams; we often tend to recognize only the accomplishments of team members "near" to us. For example, overlooking performance of someone who works in a different location and does not "see" often.

- Recency bias/spillover bias allows the most recent performance to cloud one's decision (recency) or completely overlook current improvements over past performance (spillover). For example, evaluating an individual based only on the performance for the recent quarter and ignoring their performance over the annual cycle.

- Identity bias is a bias where different standards or expectations may judge colleagues in a team. For example, women on maternity leave may be considered for lesser ratings or not considered for promotions. A common perception is how people who spend more time in the office are labeled as performers.

\section{Conclusion}

Organizations are encouraged to become self-aware, acknowledging biases and consciously eliminate them (Amis, 2020). Managers will need to assess performance based on character traits rather than objective performance parameters, and any promotion decisions will be made on data and merit achievements. Unconscious bias leads to stereotypes and erroneous decisions; it can harm employee morale and company culture. Unconscious bias can stymie efforts to create a truly diverse and inclusive workplace. Before evaluating a promotion, managers will need to analyze their own biases. Implicit or unconscious bias happens when our mind rushes to judge people and situations without realizing it. Consciously eliminating bias encourages us to be more inclusive and makes us better people at work and beyond.

\#BreakTheBias

\section{References}

Amis, J.M. (2020), "The organizational reproduction of inequality", Academy of Management Annals, Vol. 14 No. 1, pp. 195-230

Bapuji, H. and Chrispal, S. (2020), "Understanding economic inequality through the lens of caste", Journal of Business Ethics, Vol. 162 No. 3, pp. 533-551. 
Connelly, B.S. (2020), "Searching for a sign: CEO successor selection in the wake of misconduct", Journal of Management, doi: 10.1177/0149206320924119.

Damaraju, N.L. (2018), "The role of social proximity in professional CEO appointments: evidence from caste/religion-based hiring of CEOs in India", Strategic Management Journal, Vol. 39 No. 7, pp. 2051-2074.

Jones, K.P. (2014), "Managing concealable stigmas at work: a review and multilevel model", Journal of Management, Vol. 40 No. 5, pp. 1466-1494.

Martin, S.A. (2019), "Social class transitioners: their cultural abilities and organizational importance", Academy of Management Review, Vol. 44 No. 3, pp. 618-642.

Swethaa Ballakrishnen, P.F.-S. (2018), "Intentional invisibility: professional women and the navigation of workplace constraints", Sociological Perspectives, Vol. 62 No. 1, pp. 1-19, doi: 10.1177/0731121418782185.

\section{About the authors}

Ms Veena Shenoy is an Assistant Professor at ISBR Business School in Bangalore and a Research Scholar at Surathkal Karnataka, National Institute of Technology. She has 15 years of prosperous industry and academic experience. Her research interests include behavioral science, cognitive psychology, customer relationship management and managing human resources. She is a Gold Medalist from Pune University, India, and has won numerous accolades, such as the best paper awards at international conferences held at institutions of national importance. She is the Founder of SuGyan Research and Consultancy. Veena Shenoy is the corresponding author and can be contacted at: veena3172@gmail.com

Mr Mohan Kumar is working as a Practice Head for Wipro Limited. His area of expertise is in Digital Technologies, and he is deeply engaged with competency development and enabling Hyper-scale Cloud practices and is a Campus Ambassador and holds preplacement talks, Champions Inclusion and Diversity programs at Wipro. He holds an Electrical Engineering degree and MBA in HR. He has 32 years of IT experience, has worked with Wipro Limited for over 14 years and has held leadership roles. Mr Mohan is currently involved in community projects in youth leadership and provides mentorship to students pursuing Engineering, Business and Management and other courses. He has conducted workshops for over 100+ colleges and schools over the past 15 years, benefitting the youth generation.

For instructions on how to order reprints of this article, please visit our website: www.emeraldgrouppublishing.com/licensing/reprints.htm

Or contact us for further details: permissions@emeraldinsight.com 